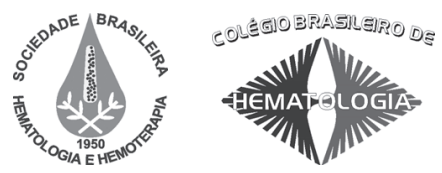

\title{
Aplasia medular após transplante hepático em pediatria
}

\section{Aplastic anemia after pediatric liver transplantation}

Marlene P. Garanito ${ }^{I}$

Jorge D. A. Carneiro ${ }^{2}$

Maria Mercês Santos ${ }^{3}$

Nelson E. M. Gibelli ${ }^{4}$

Lucy A. Matsumoto ${ }^{1}$

Uenis Tannuri ${ }^{5}$

\begin{abstract}
A aplasia de medula é uma das mais raras $(<1 \%)$ e sérias complicações após o transplante hepático por insuficiência hepática aguda grave viral não A, não B e não C. Esta condição clínica, que acomete simultaneamente o tecido hepático e o hematopoético, foi descrita pela primeira vez em 1987, por Stock, e a fisiopatologia relacionada é uma condição imunomediada, provavelmente secundária à infecção viral desconhecida, e associada a grave prognóstico. A recuperação espontânea da aplasia medular adquirida habitualmente é muito rara e $50 \%-70 \%$ dos pacientes respondem ao tratamento imunossupressor com ciclosporina A (CsA) e glubulina antitimocítica (ATG), mesmo após o transplante hepático. Além do tratamento imunossupressor, outra opção é o transplante de medula óssea (TMO). Apresentamos o caso de uma criança com aplasia medular grave após transplante hepático, por insuficiência hepática aguda grave, que recebeu tratamento imunossupressor com CsA e ATG e evoluiu com recuperação completa das três séries do hemograma. Rev. Bras. Hematol. Hemoter.
\end{abstract}

Palavras-chave: Anemia aplásica; transplante de fígado; imunossupressão.

\section{Introdução}

A aplasia de medula é uma das complicações mais graves após o transplante hepático, por insuficiência hepática aguda grave (IHAG) viral não A, não B e não C e foi descrita pela primeira vez em 1987 por Stock. ${ }^{1,2}$ Embora a incidência de aplasia medular em pacientes com hepatite aguda seja rara (0,07\%-0,22\%), nos pacientes pediátricos com IHAG e transplante hepático ela aumenta para aproximadamente 33\%.1,3 Esta complicação é mais diagnosticada nas crianças, nos adolescentes e nos adultos jovens do que nas demais faixas etárias e, se não tratada, frequentemente é fatal. ${ }^{4,5} \mathrm{~A}$ aplasia medular tipicamente manifesta-se dentro de três a quatro meses após os primeiros sintomas de IHAG e é primariamente observada nas crianças com falência hepática fulminante indeterminada, ou seja, nos pacientes portadores de hepatite, sem etiologia definida, onde foram descartadas hepatites A, B, C e outras causas de anemia como o Parvovírus B19, Citomegalovírus e Epstein-Barr vírus, nos pacientes que foram submetidos ao transplante hepático. ${ }^{2,5,6}$ Desta forma, na maioria dos casos, a causa mais comum de IHAG associada à falência medular em crianças é classificada como idiopática, apesar de considerar-se a possibilidade de alguma infecção viral desconhecida estar relacionada e o mecanismo fisiopatológico envolvido e aceito ser o imunomediado., ${ }^{2,6,7,8}$ Assim, admite-se a possibilidade de uma infecção viral da comunidade, o que poderia explicar a maior incidência nas crianças, pois muitos adultos provavelmente poderiam ser imunes. $^{9}$

O presente relato descreve o caso de um paciente que

${ }^{1}$ Médica Pediatra Hematologista do Instituto da Criança do Hospital das Clínicas - FMUSP - São Paulo-SP.

${ }^{2}$ Médico Pediatra Hematologista do Instituto da Criança do Hospital das Clínicas - FMUSP e do Centro de Hemofilia do Hospital das Clínicas - FMUSP - São Paulo-SP.

${ }_{4}^{3}$ Médica do Serviço de Cirurgia Pediátrica do Instituto da Criança do Hospital das Clínicas - FMUSP - São Paulo-SP.

${ }^{4}$ Cirurgião Pediátrico do Instituto da Criança do Hospital das Clínicas - FMUSP - São Paulo-SP.

${ }^{5}$ Professor Titular da Disciplina de Cirurgia Pediátrica da Faculdade de Medicina da Universidade de São Paulo - São Paulo-SP.

Instituto da Criança do Hospital das Clínicas da FMUSP - São Paulo-SP.

Correspondência: Marlene Pereira Garanito

Rua Venâncio Aires, 315, ap. 71 - Pompéia

05024-030 - São Paulo-SP - Brasil

E-mail:marlene.garanito@icr.usp.br/marlene.garanito@ig.com.br

Doi: 
apresentou aplasia medular grave após transplante hepático, por IHAG indeterminada, e foi submetido ao tratamento imunossupressor com ciclosporina A (CsA) e globulina antitimocítica (ATG).

\section{Relato de caso}

Paciente do sexo masculino, 11 anos, foi transferido para o nosso serviço para o tratamento de IHAG de etiologia a esclarecer (bilirrubina total $26 \mathrm{mg} / \mathrm{dl}$, TGO 300, TGP $603 \mathrm{e}$ TP $15 \%$ atividade) em dezembro de 2007 . O paciente iniciou quadro de icterícia, fezes acólicas e colúria há aproximadamente 20 dias da internação. No início do quadro, optou-se por acompanhamento ambulatorial. Contudo, o paciente evoluiu com icterícia progressiva, coagulopatia, encefalopatia e edema cerebral, sendo então internado e transferido para o nosso serviço, onde foi submetido ao transplante hepático seis dias após a admissão. As sorologias para hepatite A, B e C, assim como CMV, EBV, toxoplasmose, HIV e Parvovírus B19 mostraram-se negativas. Não havia história de viagem recente ou uso de drogas (ilícitas ou medicamentosas) e a pesquisa de autoanticorpos também se mostrou negativa. $\mathrm{Na}$ admissão, o hemograma apresentava-se normal e, por ocasião do transplante, o paciente apresentava plaquetopenia $\left(50 \times 10^{9} / \mathrm{L}\right)$. Ele foi submetido ao transplante hepático (doador falecido), sem intercorrências, e iniciou tratamento imunossupressor quatro dias após, com tacrolimus (FK) e metilprednisolona, além de sulfametoxazol-trimetropim (SMT) e ganciclovir, como profilaxia infecciosa. O exame anatomopatológico do fígado ressecado evidenciou hepatite aguda com extensas áreas de necrose pan-acinar, sem marcadores histológicos de etiologia.

O período pós-operatório foi marcado por enzimas hepáticas e bilirrubinas normais, contudo, com progressiva pancitopenia e, 13 dias após o transplante, o paciente apresentava hemoglobina de $9,2 \mathrm{~g} / \mathrm{dL}$, leucócitos de $0,14 \times 10^{9} / \mathrm{L}$, plaquetas de $12 \times 10^{9} / \mathrm{L}$ e biópsia de medula óssea com $10 \%$ de celularidade e $90 \%$ de células adiposas.

Perante o diagnóstico de aplasia medular grave secundária à IHAG de etiologia indeterminada, e após transplante hepático, foram suspensas as medicações mielotóxicas (sulfametoxazol-trimetropim e ganciclovir), substituímos o FK por CsA e o paciente recebeu tratamento imunossupressor com globulina antitimocítica de coelho (rATG - $5 \mathrm{mg} / \mathrm{kg} / \mathrm{dia}$, cinco dias). A opção pelo tratamento imunossupressor deveu-se à impossibilidade de realização do teste de HLA do paciente devido à leucopenia intensa.

Um mês após o tratamento (rATG + CsA), o paciente encontrava-se independente de transfusão de hemocomponentes $\left(\mathrm{Hb} 10 \mathrm{~g} / \mathrm{dl}\right.$, neutrófilos $6,16 \times 10^{9} / \mathrm{L}$ e plaquetas $53 \times 109 / \mathrm{L})$ e dois meses após o tratamento, em acompanhamento ambulatorial e em uso de CsA $(10 \mathrm{mg} / \mathrm{kg} / \mathrm{dia})$, apresenta hemograma normal ( $\mathrm{Hb} 12 \mathrm{~g} / \mathrm{dl}$, neutrófilos 4,27 x $10^{9} / \mathrm{L}$, plaquetas $230 \times 10^{9} / \mathrm{L}$ e reticulócitos $3.0 \%$ ).

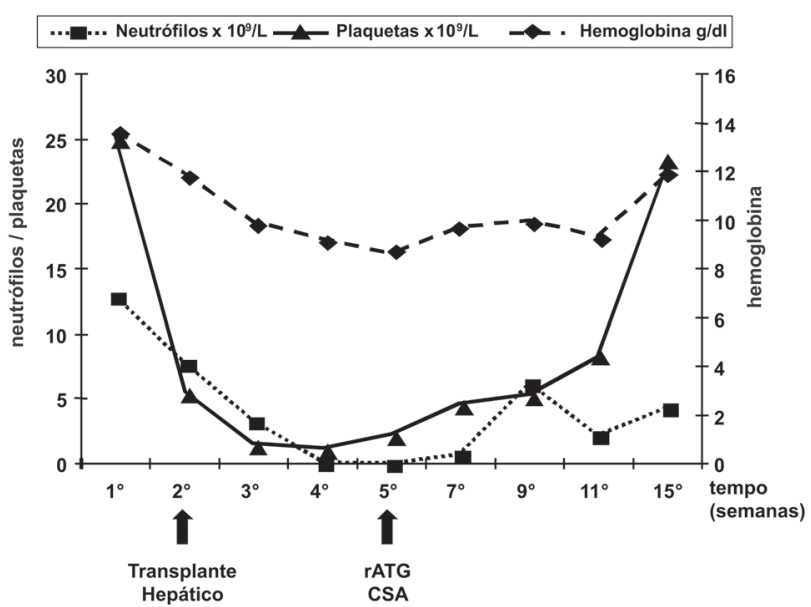

Gráfico 1. Evolução temporal dos níveis de hemoglobina, neutrófilos e plaquetas pré e pós-tratamento imunossupressor

\section{Discussão}

O diagnóstico diferencial de pancitopenia nos pacientes transplantados merece atenção especial para algumas causas específicas como a doença linfoproliferativa póstransplante, doença enxerto versus hospedeiro, medicamentos imunossupressores ou mielotóxicos, infecção aguda por CMV e Parvovírus B19. ${ }^{2}$ Uma vez confirmado o diagnóstico de aplasia medular grave, através da biópsia de medula óssea (celularidade $<25 \%$ ) associada a dois critérios no sangue periférico (reticulócitos $<1 \%$, neutrófilos $<0,5 \times 10^{9} / \mathrm{L}$, plaquetas $<20 \times 10^{9} / \mathrm{L}$ ), o tratamento deve ser instituído precocemente, considerando-se que a taxa de mortalidade é de aproximadamente $50 \%{ }^{2,10}$

Atualmente, as duas modalidades de tratamento utilizadas e discutidas são o tratamento imunossupressor e o transplante de medula óssea.

O tratamento imunossupressor, composto pela associação ATG + CsA, cuja taxa de resposta varia de 50 a $80 \%$, fundamenta-se no mecanismo imunomediado associado à fisiopatologia da aplasia medular., ${ }^{2,3,11} \mathrm{O}$ que chama a atenção é que, de acordo com a teoria imunomediada, deveríamos esperar que os pacientes transplantados e em uso de medicação imunossupressora estivessem protegidos quando comparados com os pacientes que apresentaram hepatite aguda, sem indicação de transplante hepático. E o contrário é observado, ou seja, a incidência de aplasia medular é maior nos pacientes submetidos ao transplante do que naqueles que trataram a hepatite de forma conservadora. Isto pode estar associado ao efeito mielotóxico secundário ao uso de drogas imunossupressoras e ao uso de antibióticos imediatamente após o transplante. ${ }^{3}$ Algumas drogas envolvidas na patogênese da anemia aplásica após o transplante são o FK, o SMT e a CsA. ${ }^{7}$

No caso apresentado, o quadro sugere uma infecção viral não identificada, desencadeando o processo imuno- 
mediado citotóxico causador da IHAG e da aplasia medular, pois, quando o paciente foi submetido ao transplante, já apresentava plaquetopenia e não estava em uso de drogas mielotóxicas. Dessa forma, o mesmo agente que causou a hepatite provavelmente foi o responsável pela falência medular, e o emprego de apenas uma droga imunossupressora não foi suficiente para conter o sistema imune ativado.

De qualquer forma, apesar de o quadro sugerir etiologia viral, a literatura orienta que o uso de medicamentos com potencial toxicidade medular deveria ser descontinuado. ${ }^{7}$ Por esta razão, foram suspensos o ganciclovir e o SMT, e o FK foi substituído pela CsA, uma vez que o tratamento preconiza o uso associado de CsA + ATG. ${ }^{2,8,12}$

Outros pontos que merecem destaque são o intervalo de tempo entre os sintomas e a evolução para a falência medular, pois este quadro tipicamente se manifesta dentro de dois a três meses após os primeiros sintomas clínicos de falência hepática fulminante. ${ }^{5}$ Neste caso, o paciente apresentou evolução muito rápida para falência medular, sendo o diagnóstico e o tratamento precoces fundamentais para a evolução favorável do paciente, que atingiu a independência de transfusão após 80 dias, fato este que habitualmente não se observa antes dos dois meses. ${ }^{2}$ Além disso, o paciente obteve resposta completa (hemograma normal) após exatos dois meses de tratamento.

Quanto ao transplante de medula óssea HLA compatível, a sua utilização ainda é controversa, pois, enquanto alguns grupos defendem o transplante de medula óssea (TMO) como opção terapêutica de primeira escolha, argumentando como vantagens a eliminação de complicações hematológicas tardias, como a hemoglobinúria paroxística noturna e a mielodisplasia, outros grupos reservam o TMO para os pacientes que não responderam ao tratamento imunossupressor, uma vez que o TMO está associado a significativa morbidade e mortalidade. . $^{3,7,8,9}$

Em resumo, a fisiopatologia da aplasia medular após transplante hepático por IHAG indeterminada, provavelmente deve ser secundária a agente viral desconhecido, que atua por meio de mecanismo imunomediado associadamente à mielotoxicidade relacionada ao próprio transplante e ao uso de drogas mielotóxicas de efeito cumulativo. Sendo assim, vale destacar que algumas medidas preventivas - como o não uso de drogas mielotóxicas - deveriam ser adotadas para os pacientes com alto risco de transplante hepático por falência hepática fulminante indeterminada e, além disso, o diagnóstico e o tratamento precoces podem reverter a aplasia e promover a recuperação medular. Amelhor opção terapêutica ainda é uma questão em aberto, uma vez que até o momento não há um consenso na literatura.

\section{Abstract}

Aplastic anemia $(A A)$ is one of the rarest $(<1 \%)$ and most serious complications of liver transplantation for fulminant non- $A$, non- $B$ and non-C hepatitis. It was first described in 1987 by Stock; the mechanism involved is an immunologically mediated condition secondary to an unknown viral infection. The disease is associated with a dismal prognosis. Spontaneous recovery from acquired AA is very rare however some patients (50-70\%) recover after immunosuppressive therapy, such as Cyclosporin A (CsA) and Antithymocyte globulin (ATG), even after liver transplantation. Another treatment option is bone marrow transplantation. We report on a child who developed AA following liver transplantation for fulminant viral hepatitis that was treated with intensive immunosuppression including CsA and ATG and achieved complete recovery. Rev. Bras. Hematol. Hemoter.

Key words: Anemia; aplastic; liver transplantation, immunosuppression.

\section{Referências Bibliográficas}

1. Umeda K, Adachi S, Watanabe K, Kimura N, Lin Y, Nakahata T. Successful hematopoietic stem cell transplantation for aplastic anemia following living-related liver transplantation. Bone Marrow Transplant. 2002;30(8):531-4.

2. De Bruyne RM, Dhawan A. Bone marrow dysfunction following pediatric liver transplantation. Pediatr Transplant. 2005;9(4): 423-6.

3. Itterbeek P, Vandenberghe P, Nevens F, Fevery J, Aerts R, Yap SH, et al. Aplastic anemia after transplantation for non-A, non-B, non-C fulminant hepatic failure: case report and review of the literature. Transpl Int. 2002;15(2-3):117-23.

4. Perkins JL, Neglia JP, Ramsay NK, Davies SM. Successful bone marrow transplantation for severe aplastic anemia following orthotopic liver transplantation: long-term follow-up and outcome. Bone Marrow Transplant. 2001;28(5):523-6.

5. Brown KE, Tisdale J, Barrett AJ, Dunbar CE, Young NS. Hepatitisassociated aplastic anemia. N Engl J Med. 1997;336(15):1059-64.

6. Molina RA, Katzir L, Rhee C, Ingram-Drake L, Moore T, Krogstad $\mathrm{P}$, et al. Early evidence of bone marrow dysfunction in children with indeterminate fulminant hepatic failure who ultimately develop aplastic anemia. Am J Transplant. 2004;4(10):1656-61.

7. Maheshwari A, Mishra R, Thuluvath PJ. Post-liver-transplant anemia: etiology and management. Liver Transpl. 2004;10(2): 165-73.

8. Hadzic N, Height S, Ball S, Rela M, Heaton ND, Veys $\mathrm{P}$, et al. Evolution in the management of acute liver failure-associated aplastic anaemia in children: a single centre experience. J Hepatol. 2008;48(1):68-73.

9. Tung J, Hadzic N, Layton M, Baker AJ, Dhawan A, Rela M, et al. Bone marrow failure in children with acute liver failure. J Pediatr Gastroenterol Nutr. 2000;31(5):557-61.

10. Kurre P, Johnson FL, Deeg HJ. Diagnosis and treatment of children with aplastic anemia. Pediatr Blood Cancer. 2005;45(6):770-80.

11. Bacigalupo A. Aplastic anemia: pathogenesis and treatment. Hematology Am Soc Hematol Educ Program. 2007:23-8.

12. Marsh JC. Management of acquired aplastic anaemia. Blood Rev. 2005 May;19(3):143-51.

Avaliação: Editor e dois revisores externos

Conflito de interesse: sem conflito de interesse

Recebido: 18/03/2009

Aceito após modificações: 08/07/2009 